\title{
Determinants of Factors Influencing Capacity of Small and Medium Enterprises (SMEs) in Employment Creation in Lagos State, Nigeria
}

\author{
Kayode E. Bowale ${ }^{1} \&$ Afred O. Ilesanmi ${ }^{1}$ \\ ${ }^{1}$ Adekunle Ajasin University, Akungba-Akoko, Ondo State, Nigeria \\ Correspondence: Kayode E. Bowale, PhD, Lecturer, Adekunle Ajasin University, Akungba-Akoko, Ondo State, \\ Nigeria. Tel: 234-80-346-4522. E-mail: kayobowale@yahoo.co.uk
}

Received: July 19, 2013

doi:10.5430/ijfr.v5n2p133
Accepted: March 10, 2014

Online Published: April 1, 2014

URL: http://dx.doi.org/10.5430/ijfr.v5n2p133

\begin{abstract}
This study analyzed the characteristics of Small businesses (SBs) in Lagos, Nigeria and examined factors influencing the capacity of SMEs to create employment in Lagos in Southwest, Nigeria. Primary data were used for this study. The target population was all small businesses in Lagos State. The choice of the study area was based on size and concentration of SMEs. Data were collected using questionnaires from a sample of 180 small firms. The selection of respondents was done using two- stage stratified sampling procedures. In the first stage, five local governments with highest number of SMEs concentration were selected. In the second stage, using systematic sampling on the list of all the SMEs in the selected local governments, a total 36 SBs were selected systematically from each local government area in the five LGAs in Lagos state. The data collected were analysed using appropriate descriptive statistics and inferential techniques. The results showed that majority (75\%) of surveyed SMEs operating in the study area were microenterprises employing less than 10 workers while only (19\%) and (6\%) of the respondents engaged in small scale and medium scale enterprises employing between 10 and 50 workers respectively. The results also showed that there was substantial increase (133\%) in number of SMEs owners that have grown in terms of employment generation from microenterprises to small scale and medium firms over the span of five years. The result showed further that business registration, business size, nature of business, sources of capital, were the major factors determining both income and employment generation potentials of SMEs. The study concluded that age of business, education, and sources of raw materials were only significant in influencing the capacity of SME to generate employment.
\end{abstract}

Keywords: small and medium enterprises, employment creation, Lagos State

\section{Introduction}

The fight against unemployment has been one of the key challenges facing the African continent in general and the Nigerian economy since independence. Government at various levels has long recognized the need to promote the development of SMEs in order to reduce poverty; stimulate employment; mobilize local resources; reduce migration from rural to urban area and disperse industrial enterprise more evenly across the country. This prompted the establishment of various policy reforms and programmes. the National Directorate of Employment (NDE); National Economic Reconstruction Fund (NERFUND); World Bank Assisted Loan Scheme (WBALS); Nigeria Export and Import Bank (NEXIM); Nigeria Bank for Commerce and Industry (NBCI), Nigeria Industrial Development Bank (NIDB); the establishment of Community Banks (now Microfinance banks) and the Peoples Bank. The failure of these programmes in the past has brought a renewed focus from the macro perspectives of tackling unemployment to micro-perspectives through the promotion of SMEs from both the government and the private sector.Small enterprises development are expected to contribute to poverty alleviation by creatimg jobs either through start up of new enterprises or expansion of existing ones. Job creation provides income to the poor.

There is a great concern among the policy makers and researchers on the performance of the small and medium enterprises in Nigeria. Literature is replete with researches on the relationship between SMEs development and poverty alleviation in terms of income and employment creation. But these researches have concentrated on the aggregate effects of SMEs, neglecting different traits of firms and countries as well as the issues relating to business formality. There is no consensus on whether registered SMEs performed better than those that were not registered. The broad objective of this study is to examine the factors that influence the capacity of small businesses in 
employment creation in Lagos, Nigeria. Specifically, the study analyses the characteristics of SMEs and assesses the performance of small firms in employment creation and factors influencing their capacity in this regard.

\section{Literature Review}

Globally, governments are giving attention to development of small and medium enterprises(SMEs). Studies have shown that development of SMEs serves as a way of developing human capital and creating jobs(Brana, 2008, Cheston \& Kuhn, 2002, Shane, 2003).

Small and Medium Enterprises (SMEs) have also been believed to be important in supporting economic development within a country (e.g. Akhtar; CDASED, 1999; Mazzarol, Volery, Doss, \& Thein, 1999). One of the important roles of SMEs in this context includes poverty alleviation through job creation. In Nigeria there is a need for policy makers and analysts to know the characteristics and possible impact of SMEs on economic growth and poverty reduction.

Literature is replete with different ways of classifying SMEs. Researchers such as Akerele (2000) classified SMEs as formal and informal SMEs, rural and high technology and knowledge driven small scale enterprises. SMEs in the informal sector are difficult to control as they fall outside the modern or formal sector of the economy. In most cases, these informal SMEs are based on indigenous technology e.g dyeing, pot making and brick making. However they contribute job creation (Fluitman, 1989). Many of these enterprises usually make use of simple and crude method of production (Dutta, 2005). Those SMEs in the formal sector are usually registered under the statutory company laws. Another classification of SMEs is the rural based SMEs. Some believe that rural enterprises must necessarily have a direct relationship with agriculture. It is important to know that diversifying rural economy through promotion of small business would amount to rural industrialization. Classification can also be viewed from the angle of the size of business. The United Nations Development Programme in its study UNDP (1988) defines micro enterprise as business engaging one to four employees while small enterprises are those with 5 to 25 employees. Others have classified those enterprises engaging 1 to 9 employees as micro enterprises and those engaging 10 to 49 as small enterprises while those engaging 50 to 300 employees as medium enterprises (CBN 2005). We have adopted this classification in our study. In spite of various opinions on the classification of SMEs, there are common characteristics of SMEs. These include crude technology, lack of capital and low level of education of business owners (World Bank, 2005).

It is important to also know that a lot of studies have been carried out on the role of SMEs in income generation and employment creation. Understanding the connection between small businesses, economic growth and the incidence of poverty has been the interest of many researchers and there have been many attempts to establish statistical relationships between official poverty rates and overall macroeconomic performance on the basis of aggregate time series data (Freeman, 2002; Haveman and Schwabish, 2000; Blank, 2000; Cain, 1998; Powers, 1995;Blank and Card, 1993; Cutler and Katz, 1991; Blank and Blinder, 1986; Gottschalk and Danziger, 1985). The results from these studies show an inverse relationship between economic growth and poverty rates. Blank and Blinder (1986), for example, found that both the unemployment rate and the inflation rate were positively related to poverty rate, with a high quantitative effect of unemployment. Cutler and Katz (1991), Blank (1993) and Powers (1995) also found similar results apart from the post recession period of the 1980s where unemployment rate was found to be inversely related to poverty rate. Using GDP growth rate as explanatory variable, Haveman and Schwabish (2000) tested the differential effect of macroeconomic performance on the poverty rate for various periods. Their result shows a strong inverse relationship between economic growth and poverty rate. They also showed that a one-percentage decrease in unemployment rate was associated with a 0.43 percentage point decrease in poverty rate between 1993 and 1998. Beck (2005) provided cross-country evidence on whether SMEs boost economic growth, alleviate poverty, and reduce income inequality. They find a strong, positive association between the size of the SME sector and the rate of economic growth. But, they do not find that SMEs cause growth. Furthermore, the comparisons do not indicate that SMEs exert a particularly beneficial impact on employment or income distribution. Anyawu(2001) explained that although, there were many bottlenecks in the growth and development of enterprises in Nigeria such as difficulties in local sourcing of raw materials, capital inadequacy, poor managerial and technical knowhow, as well as infrastructure deficiencies, the problem of long-term funds and working capital has pre-eminence. Olashore (1987) opines that the ability of SMEs to borrow is limited by the small scale amount to assets it owns and the fact that it cannot raise capital from the organized capital. Olowu (1983) argued that the major problem of SMEs consists of finance, organization and technology. The finance problem derives from the fact that the bulk of the funds available to it are originally from the owner of the enterprises. Babalola (1982) suggested that if the small and medium scale enterprise could be given attention in an economy, it could play an important role in arresting the persistent decline 
in the value of enterprises. It could be counted upon for promoting stability and growth in GDP through the quick returns it generates.

\section{Research Methodology}

\subsection{Study Area}

The study was conducted in Lagos State Nigeria. Owing to the cosmopolitan nature the fact that the state represents the economic hub of the country, the state has the largest concentration of all forms of medium and large scale in the country (NSB, 2005). The presence of the sizeable proportion of business might also be attributed to its proximity to the seaports and the fact that Lagos which is one of the states in the region was the former seat of power of Federal Government of Nigeria. The growing number of small and medium scale enterprises (SMEs) in the area attests to this fact. Consequently, the state reflects the typical Nigeria business environment and has a good representation of all characteristics that shape the business environment and economy of Nigeria.

\subsection{Population, Sampling Procedure and Size}

The target population all registered small and medium scale businesses in Lagos, State, Nigeria. The choice of these the state is based on size and concentration of SMEs. Based on the National Bureau of Statistics SMEs Census (NBS, 2010), the number of questionnaires administered was based on the number of SMEs that were identified in the local governments selected for the survey. A sample of 260 respondents was administered for a period of three weeks. A returned rate of about $70 \%(180)$ was recorded. These were the ones correctly filled and considered valid.

\subsection{Variables Description}

The questionnaire covers data on socio-demographic profile of respondents, the characteristics of SMEs and factors influencing the capacity of SMEs to create employment. The data collected are analysed using appropriate descriptive statistics and inferential techniques. The sampling frames for the survey consists of SMEs which employ not more than 10 for micro, 50 people for small(SSEs) and 250 for medium(MEs). Since not all the SMEs are formally registered with government and even trade associations, the population size cannot be exactly pre-determined. The critical factors identified include owner's sex, education, motivation, for starting their businesses, activities undertaken before establishing their current business, sources of initial capital, business registration and technology being used.

\subsection{Analytical Technique}

The tools of analysis are t-test for difference of two means and multiple regression models. The t-test of significance variables and models was performed at alpha levels of one (1), five (5) and 10\%.

\subsection{Model Specification}

The analysis of the factors influecing capacity of SMEs to create jobs was examined by estimating a Probit model. The model regresses the probability of whether SMEs is able to alleviate poverty on a set of both economic and non economic factors. These model variables have been identified as growth determinants of firms (and thus determinants of employment growth). These include the characteristics of business owners such as ownership structure, level of education, activities undertaken before establishing their current business, motivation for starting businesses, sources of initial capital, business registration and the types of technology used.

The probit model is known to produce statistically sound results. The model is also known to produce results that can be easily interpreted and the method is simple to analyse in economics applications. Furthermore probits model is one of the most popular binary response model used in empirical analysis. The probit model for this study is specified as follows:

$$
y=\alpha_{0}+\alpha_{1} x_{1}+\alpha_{2} x_{2}+\alpha_{3} x_{3}+\alpha_{4} x_{4}+\alpha_{5} x_{5}+\alpha_{6} x_{6}+\alpha_{7} x_{7}+\alpha_{8} x_{8}+\alpha_{9} 9+e_{1}
$$

In a more compact form, equation (3.1) can be re-written as

$$
y_{i}=\sum_{i}^{n} \alpha_{i} x_{i}+e_{i}
$$

Where:

$y_{i}=$ Poverty measures (profit, turn over owners satisfaction). If the probability of making profit is high, 1 and otherwise, 0 .

$x_{1}=$ Age (years); 1 for above 5 years and 0 for otherwise

$x_{2}=$ Gender; 1 for male and 0 for female 
$x_{3}=$ Education; 1 for post secondary and 0 for otherwise

$x_{4}=$ Source of start up capital (N); 1 for personal and 0 for otherwise

$x_{5}=$ Sources of raw material; 1 for local and 0 for imported

$x_{6}=$ Business size; 1 for micro and 0 for otherwise

$x_{7}=$ Business Registration; 1 for registered and 0 for otherwise

$x_{8}=$ Nature of factor Intensity, 1 for Labour intensive, 0 , otherwise

$x_{9}=$ Nature of Business, 1 for trading, 0 , otherwise

$\alpha_{0}=$ Constant (A);

$\alpha_{i}=$ Regression Coefficients;

$e_{i}=$ Error term.

\section{Empirical Results}

\subsection{Analysis of Socio-Demographic and Economic Characteristics of Respondents}

The age structure of the respondents was classified into six groups. Only $(0.4 \%)$ of the respondents are above 60 years of age and less than ten percent (8\%) is less than 20 years of age. (32\%) were between the ages of 20 to 30 while (28\%) of the SMEs owners were between 30 and 40 years of age. (22\%) of the respondents were not older than 50 years but above 40 years. This suggests that the bulk $(82 \%)$ of the SMEs owners were in their middle ages (20 to 50 years) with only (10\%) of the respondents between 50 and 60 years of age. The age structure reflects the fact that most of the respondents are mature and they are the people whose economic reality and the survival instinct must have driven into the establishment of the businesses.

The educational qualification of these business owners was also explored. The level of education and literacy is very high among the SMEs business owners in the southwest, Nigeria. At least $94 \%$ of the business owners read and write and attended a minimum of primary education. The proportion of graduates among the SMEs owners is also encouraging, at least $45 \%$ of the SMEs owners attended one higher institution or the other. The proportion of those without any form of education, though small, is significant in view of the fact that about $(6 \%)$ out of the businesses surveyed were still managed by people who lack the minimum ability to read and write. The implication of this is that this set of business owners may not be able to key in to the global trend of Information and Communication Technology and e-business.

Most of the business owners (57\%) were married. Only (26\%) were single and (17\%) of the business owners were either divorced or widowed. In essence the bulk of the business owners were people who had family responsibility and the presumption is that their drive to establish the businesses might not be unconnected with the need to meet up with their economic and social responsibilities even if they are single parents. Also it was observed that most of the SMEs owners concentrated on one business at a time, only (28\%) of the owners claimed that they had more than one business.

\subsection{Nature and Type of SMEs Businesses in Lagos}

The characteristics of businesses also formed part of the background information that was examined before the assessment of the role of businesses. The distribution patterns of the SMEs with respect to nature of businesses engaged in, size of business, ownership structure and years of operation.

\subsubsection{Nature of Business}

By nature of business, five major business lines were predominant among the south western state SMEs; these are agro-allied business, like food processing, trading, light manufacturing, transports and Vocational and professional service providers. Among these five lines of business, trading is the most common form of businesses that the SMEs engaged in (39\%)). This is followed by Light Manufacturing, (22\%) and Vocational and professional services providers (20\%). The least is transport business while a substantial proportion (17\%) also engaged in agro-allied business. The low proportion of transport business was because most of the transport owners do not consider themselves as part of the trade association. They have their Union -National Union of Road Transport Workers (NURTW), which was not the focus of this research. Expectedly, the trading business remained the dominant business. This is a reflection of the Nigerian economy that is more of consumer state. 


\subsubsection{The Size of Business}

The SMEs were also classified into three, according to the number of the employees. Those SMEs with less than 10 workers are regarded as microenterprises, those with not more than 50 workers are the small scale enterprises and the SMEs with above 50 workers but below 250 are called the medium enterprises. The majority $(75 \%)$ of SMEs operation in the southwest Nigeria were microenterprises with less than 10 workers. The proportion of the small scale business is $(19 \%)$ while medium scale was only $(6 \%)$. There are two reasons for such a pattern, the cost of establishing the bigger business may be enormous and out of reach of most of the potential owners. Secondly, the high incidence of poverty among the peoples had hindered their ability to engage in large scale business enterprises.

\subsubsection{Ownership Structure}

The distribution of respondents by the ownership structure shows that the bulk of the enterprise $(73 \%)$ is one- man business. Twelve percent of the SMEs business were family joint business while (11\%) are owned by different people who are not from the same family. Four percent of the respondents claimed that their businesses were owned by friends. The ownership structure also conforms to earlier observation that most of the businesses are microenterprises of less than ten workers with little start up capital. The idea of social recognition and self esteem among the Nigerians might have contributed to the ownership structure observed. In this part of the world most people are skeptical in engaging in joint business.

\subsubsection{Year of Operation}

It is a generally held view in the literature that most SMEs collapse within five years of establishment. This proposition was also factored into the information collected from the respondents by asking for the years of establishment of their businesses. Most of the businesses $63 \%$ were established within the last five years. Twenty-two percent of the SMEs were established within the last ten years while only $15 \%$ had been in operation for more than 10 years. Though, it could be said that the proportion of business that fall below five years are higher, the fact that a sizeable number of the businesses are older than five years implies that the survival rate of the SMEs business in the Lagos is high and improving. The distribution pattern also shows that two out of every five SMEs in the Lagos will survive more than five years and at least two of every ten survive above ten years.

\subsection{Economic Profile of SMEs in Lagos, Nigeria}

The SMEs ability to generate income and employment thereby contributing to reduction in poverty level and incidence as well as its prevalence depends on the performance of the SMEs in terms of income, employment, sales, profitability and growth potential. To determine these parameters and then juxtapose them with the indicators of poverty reduction, this section explores some of the possible sources of the strength of SMEs to generate income and employment. These factors are divided into two categories: Those factors that relate to the sources of input and material that are used in the production of goods by the SMEs while those that relate to the changes in sales and profitability of the business. These two sets of factors determine SMEs performance. The SMEs owners who were the respondents in this survey were asked to respond to questions relating to these issues.

\subsubsection{Sources of Raw Materials}

The distribution of the respondents according to the sources of raw materials implies that most of the respondents (64\%) sourced their materials locally. Only $12 \%$ of the SMEs claimed that the bulk of their raw materials were from other countries. The SMEs, because of the nature of their businesses, tend to use local raw materials and the use of these materials tends to generate ripple and multiple effects on the local productive capacity. Since the raw materials used by these SMES are in most cases the output of some other industries, they tend to increase the productive capacity of other business and hence the possibility of generating higher domestic employment and also income.

\subsubsection{Sources of Finance}

Four sources were identified. These are personal savings, cooperative society's loans, bank loans and family remittance or inheritance. Of these four sources of finances, personal savings (61\%) was the most frequently cited sources of finance by SMEs. The second most commonly cited sources of finance are cooperative society loans (23\%). Only $7 \%$ and $9 \%$ of the SMEs claimed to have ever sourced finances from the banks and family inheritance respectively. The informal nature of cooperative society financial support has made it the toast of almost all small scales business owners. However, the low patronage of formal banking system for finance by SMEs still underscore the non integration of the SMEs into the formal financial system. 


\subsubsection{Sources of Capital Equipment}

One of the essences of SMEs development is to kick start the industrial base of the economy. To do that the capital input to use is critical. If the SMEs get their capital equipment from domestic market it implies that the technological base of the economy is improving. It suggests that there is both backward and forward linkages among the industries. It is this realization that made the survey to include a question on the sources of the capital equipment used by the SMEs. The distribution of responses shows that only $13 \%$ of the SMEs depend solely on imported equipment. About $37 \%$ of the respondents claimed to source their capital equipment locally while the majority $(50 \%)$ of the SMEs reported that they acquired their equipment from both local and international markets. The level of technological knowhow is also low and there is not much industrial equipment manufacturing in Nigeria. Even those machine fabrication industries are critically ill and comatose due to negligence, this has added to the need for sourcing the needed equipment from abroad. Many of the SMEs also face the challenges of financial constraint of importing this equipment.

\subsubsection{Nature of Factors of Production}

Owing to little exposure to technology coupled with the fact that majority of the SMEs owners do engage in trading with little interest in manufacturing, most of the activities are labour intensive. In the survey, $92 \%$ of the SMEs were involved in labour intensive activities while only $8 \%$ engaged in capital intensive activities.

\subsection{Assessment of Income and Employment Generating Capacity of SMEs}

\subsubsection{Income Generation}

The assessment commenced by looking at the position small businesses occupied as a source of disposable income. $77 \%$ of the respondents ranked small businesses as their top income source. Micro enterprises owners sourced their income mainly from their business and $85 \%$ of small scale enterprises (SSEs) while $67 \%$ of the medium scale enterprise owners sourced their income from their business. This suggests that the SMEs businesses constitute the main source of livelihood for the owners.

\subsubsection{Employment Creation}

Small businesses in developing countries have been long recognized to play a dynamic role through which employment growth can be achieved. Apart from the fact that employment growth is a measure of economic growth; for the entrepreneur, it can also serve as an indicator of his/her success and for the business as a whole, it is a measure of economic contribution of the firm to the common good. Moreover, according to Child (1973), employment is an adequate criterion for the measurement of the size of an organization.

This study also assessed the ability of small businesses to generate employment opportunities. Findings showed that employment growth occurred within the Micros i.e. three employees per SSE over an average period of 4 years in operation, while MEs also increase their employment levels giving an overall annual employment growth of $45 \%$. The Micro enterprise has more potential to growth than the other two types of SMES. It grew by about $133 \%$ while SSE and ME grew by $75 \%$ and $45 \%$ respectively. To further analyze income generation for employees, this study focused on salaries earned by people employed in small businesses. The respondents were requested to indicate salaries and wages. The results showed that salary levels varied with the size of enterprises. MEs offered higher salaries of about N 30, 000 per month, compared to N 10,000 offered by Micros. In income terms for medium enterprises, salaries earned were well above the official minimum wages of N18, 000 per month prevailing in the Nigeria. It is also above the estimated basic need poverty line of N6, 000 per month based on the $\$ 1$ per day.

\subsection{Regression Analysis of Socio-Economic Factors Influencing SMEs Capacity in Poverty Alleviation}

Probit regression model was specified to analyze the possible factors that may influence SMEs potential to alleviate poverty.

Age of the business has negative and insignificant effect on the capacity of the SMEs to generate income. The drive to success is higher in new entrepreneur and they are ready to do everything possible to promote the business than market pricing, aggressive marketing, after sales services and many others. The urge to create their own set of customers and to also be a big player in the market makes them to want to achieve greater performance. As they also become contented with their new status and business owners and they have moved from poor to relatively rich, the urge slows down and the ability to drive the business reduces and profit and income fall to an average level. Also the fact that most of the business owners were either unemployed, retrenched, retired or had no stable source of income made them to be more aggressive than the existing business owners. 
However, the results of estimation of employment generation show that age of the business is positive and significant. This is in line with a prior theoretical expectation. The result shows that the older the age of the business the higher the number of jobs and employment it will generate. Theoretically, there is a level of employment at which diseconomies of scale set in. At this stage, addition to employment of labour to fixed capital equipment leads to reduction in productivity and diminishing returns will set in. Since most of the firms hardly watch out for this level then there is a tendency for most of the firms who were more interested in growing the size of their business to end up in reducing their capacity to generate profit.

The results of Business registration are interesting and counter intuitive. The coefficients on the Business registration are negative and significant. This suggests that registration of business was perceived as factor that may hinder the ability of the business to generate income and employment thereby contributing to poverty alleviation. Intuitively, business registration rather than hindering the promotion of SMEs; should boost their status and give them more recognition which invariably leads to higher employment and income generation. The registered business owner should be able to take up many new business opportunities that required formal registration and able also to benefit from government incentives. Thus business registration should rather serve as an incentive than disincentives to enhancing the capacity of the SMEs to employment and income generation and enhance reducing poverty incidence among the SMEs owners. One major reason for this counter intuitive result might strongly be due to the lack of adequate information about the importance of business registration. Also, the experience of some of those business owners who had attempted to register was bad. In many instances, the process of registration is cumbersome and relatively expensive. More importantly it is full of scams and also in most cases the registered business faced a lot of multiple taxations from the three tiers of government. Since those who do not register operate and get away with it, then many new and existing businesses would be discouraged to register and will perceive registration as hindrance to their business survival. The result of the business size corroborates the results on age of business. The coefficient on size is negative and significant. This implies that smaller SMEs experienced higher growth in income and employment generation. Nature of business and factor intensity were also negative and significant. This suggests that expanding the business across other business may hinder the ability of the business to generate more income and employment. The main possible reason for this could be that as the number of business increases, the ability to manage the business effectively declines. The decline in managerial ability possibly affects the income generation capacity and consequently the poverty alleviation ability of SMEs. The sources of raw material whether local or foreign had positive sign and significant effect on employment which also implies that locally sourcing of raw materials tend to alleviate poverty. The sources of finance and capital equipment had negative effects and also might hinder the capacity of SMEs to generate income and reduce poverty by the SMEs.

Table 1. Summary of results for the probit regression

\begin{tabular}{lllllll}
\hline Variables & \multicolumn{1}{l}{ Income Model } & \multicolumn{5}{c}{ Employment model } \\
\hline & Coef & Z-stat & P-value & Coef & Z-stat & P-value \\
\hline Age of Business (AGE) & & & & & & \\
\hline Business Registration (BR) & -0.08 & -0.67 & 0.50 & 0.51 & 4.54 & $0.00^{* * *}$ \\
\hline Business size( BS) & -0.19 & -1.79 & 0.07 & -0.72 & -5.33 & $0.00^{* * *}$ \\
\hline & -0.52 & -3.93 & $0.00^{* * *}$ & -0.47 & -3.90 & $0.00^{* * *}$ \\
\hline Education Level of owners (EDU) & 0.17 & 1.61 & 0.11 & 0.45 & 2.99 & $0.00^{* * *}$ \\
\hline & & & & & & \\
Nature of factor intensity (FOP) & -0.30 & -2.44 & 0.01 & -0.08 & -0.74 & 0.46 \\
\hline Nature of Business (NOB) & -0.48 & -4.42 & $0.00^{* * *}$ & 0.67 & 4.87 & $0.00^{* * *}$ \\
\hline & & & & & & \\
Sources of raw materials (RM) & 0.06 & 0.50 & 0.62 & 0.75 & 6.63 & $0.00^{* * *}$ \\
\hline Sources of capital Equipment (SOC) & -0.18 & -1.79 & 0.07 & 0.56 & 4.73 & $0.00^{* * *}$ \\
\hline & & & & & & \\
Sources of Finance (SOF) & -0.53 & -4.87 & $0.00^{* * *}$ & -0.06 & -0.55 & 0.58 \\
\hline & & & & & & \\
Staff Strength (STS) & 0.51 & 4.39 & $0.00^{* * *}$ & 0.09 & 0.80 & 0.42 \\
\hline Constant (C) & 1.06 & 5.37 & 0.00 & -2.25 & -8.87 & 0.00 \\
\hline
\end{tabular}




\begin{tabular}{lll}
\hline & & \\
\hline McFadden R-squared & 0.07 & 0.19 \\
\hline S.D. dependent var & 0.50 & 0.48 \\
\hline Akaike info criterion & 1.31 & 1.08 \\
\hline Schwarz criterion & 1.38 & 1.15 \\
\hline Hannan-Quinn criter. & 1.34 & 1.11 \\
\hline Restr. Deviance & 962.80 & 902.60 \\
\hline LR statistic & 72.19 & 169.95 \\
\hline Prob(LR statistic) & 0.00 & 0.00 \\
\hline
\end{tabular}

*** Significant at $1 \%$ level

Note: In income model, the dependent variable is the income generation capacity (in terms of profit margin and disposable income) of firms, whilst in employment model, the dependent variable is the employment creation capacity of the firms.

\section{Conclusion}

In general, business registration, business size, nature of business, Sources of capital are significant factors determining both income generation and employment generation potential of the SMEs in Lagos. However, age of business, educational level and sources of raw material were only significant in influencing the capacity of SME to generate employment, on the other hand, nature of factor intensity, sources of finance and staff strengths were only significant in income generation capacity of the SMEs. Therefore factors influencing SMEs contribution to poverty reduction differ across the different components of Poverty reduction measures in the state.

\section{References}

Akhtar, M. R. (1997). Partnership Financing of Microenterprises. International Journal of Social Economics, 24(12), 1470-1480. http://dx.doi.org/10.1108/03068299710193930

Blank, R. M. (1997). It Takes a Nation: A New Agenda for Fighting Poverty. Princeton NJ; Princeton University Press.

Blank, R., \& D. Card. (1993). Poverty, Income Distribution, and Growth: Are they Still Connected? Brookings Papers on Economic Activity, 2, 258-339.

Brand, V., Mupedziswa, R., \& Gumpo, P. (1995). Structural Adjustment, Women and Informal Sector Trade in Harare. In Gibbon P (Ed.), Structural Adjustment and the Working Poor in Zimbabwe. Nordiska Afrikainstitutet: Uppsala.

Chambers, R. (1983). Rural Development-Putting the Last First. Longman, Malaysia.

Clarke, G. (1995). More Evidence on Income Distribution and Growth. Journal of Development Economics, 47, 403-427. http://dx.doi.org/10.1016/0304-3878(94)00069-O

Cutler, D., \& Katz, L. (1991). Macroeconomic Performance and the Disadvantaged. Brookings Papers on Economic Activity, 2, 1-74. http://dx.doi.org/10.2307/2534589

Dickey D.A., \& Fuller, W. A. (1981). Likelihood Ratio Statistics for Autoregressive Time Series. Econometrics, 105-1072.

Dutta, S. (2005). Dynamics in the Small and Medium Enterprises Sector in Indonesia. Edinburgh University Press, London.

Engle, R. F., \& Granger, C.W. (1987). Cointegration and Error - Correction: Representation, Estimation and Testing. Econometrica, 251-276. http://dx.doi.org/10.2307/1913236

Fluitman, M. (1984). Training for the Work in the Informal Sector, ILO Geneva 1984 Training Ed.

Gebremania, G.H. (2004). The Role of Small Business in Economic Growth and Poverty Alleviation in West Virginia. An Empirical Analysis. Research Paper 2004-10.

Goldsmith, W.W., \& Blakely, E.J. (1992). Separate Societies: Poverty and Inequality in American Cities. Philadelphia. Temple University Press. 
Gottschalk, P., \& S. Danziger, (1985). A Framework for Evaluating the Effects of Economic Growth and Transfers on Poverty. The American Economic Review, 75(1), 153-161.

Kilby, D.D. (1969). Urban Employment and Small and Medium Scale Enterprises.

Kirk-Green, A., \& D. Rimmer. (1981). Nigeria Since 1970. London: Hodder and Stroughton.

Kirlby, P. (1969). Industrialization in an Open Economy Nigeria 11945-66. Cambridge, University Press.

Kretzman, J.P., \& Mcknight, J.L. (1993). Building Communities from the Inside Out. Chicago; CTA Publications.

Lewis, W.A. (1955). The Theory of Economic Growth. Allen and Unwin: London.

Okpara J.O. (2011). Factors Constraining the Growth and Survival of SMEs in Nigeria: Implications for Poverty Alleviation. Management Research Review, 34, 156-171. http://dx.doi.org/10.1108/01409171111102786

Onwumere, J. (2000). The Nature and Relevance of SMEs in Economic Development (October ed). The Nigerian Banker, p. 17.

Patrianila, V. N. (2003). Italia Besarkan UKM Dengan. Pengusaha, (32), 70-71.

Powers, E. T. (1995). Growth and Poverty Revisited. Economic Contemporary, Federal Reserve Bank of Cleaveland.

Ryan, W. (1976). Blaming the Victim. New York: Vintage.

Sen, A. (1984). Poverty and Famines. An Essay on Entitlements and Deprivation. Claredon. Press, Oxford.

Shane. (2003). A General Theory of Entrepreneurship. The Individual- Nexus. UK. Edward Elgar.

Soludo, D. (2004). Challenging of Redney Poverty in Nigeria. Paper Delivered at the Annual NIB Lecture on Sustainable Reforms in the Banking Sector, September 3, 2003.

Townsend, P. (1974). The Concept of Poverty, Working Papers on Methods of Investigation and Lifestyles of the Poor in Different Countries, Heinemann, London.

Udechukwu F.N. (2004). Survey of Small and Medium Scale Industries And their Potentials in Nigeria.

United Nations Development Programme (UNDP Nigeria). (2002). A Six- State Study of Poverty in Nigeria.

World Bank. (1994). Sub-Saharan Africa: From Crisis to Sustainable Growth, Washington. 